\title{
Prevalence and husbandry-related risk factors of myiasis in domestic cavies in the western highlands of Cameroon
}

\author{
M. K. KOUAM ${ }^{1,2}$, F. MEUTCHIEYE ${ }^{1}$, E. MIEGOUE ${ }^{1}$, T. T. NGUAFACK ${ }^{1}$, \\ J. TCHOUMBOUE ${ }^{1}$ AND A TEGUIA ${ }^{1}$ \\ ${ }^{1}$ Department of Animal Production, Faculty of Agronomy and Agricultural Sciences, Dschang, Cameroon \\ ${ }^{2}$ Center for Research on Filariasis and other Tropical Diseases (CRFilMT), Yaoundé, Cameroon
}

Received 27 March 2016; Final revision 13 September 2016; Accepted 28 September 2016; first published online 26 October 2016

\section{SUMMARY}

The presence of parasites on the farm can be a cause of losses in animal production, and often a threat to public health. A cross-sectional study was carried out in rural areas of the western highlands of Cameroon to determine the prevalence and husbandry-related risk factors associated with Cordylobia anthropophaga infestations in domestic cavies. The overall prevalence of myiasis in animals was $2 \cdot 80 \%$ [95\% confidence interval (CI) $1 \cdot 50-5 \cdot 10]$; myiasis was found in $2 \%$ and $4.30 \%$ animals in Menoua and Bamboutos divisions, respectively. Eleven farms (8.95\%) in total were infested with $C$. anthropophaga, with $6 \cdot 41 \%$ and $13.34 \%$ of farms in the Menoua and Bamboutos divisions, respectively. The relative risk of infestation within each factor showed that the risk of myiasis in animals kept in kitchen compartments without litter was $6 \cdot 16$ times higher (95\% CI 1.71-22.29, $P=0.04)$ than in animals kept in kitchens and house floors. Despite the low prevalence, the burden of cordylobiasis needs to be assessed. It is assumed that the risk of humans acquiring the disease is higher in farmers keeping cavies in kitchen compartments without litter. Farmers need to be educated on control measures to reduce the risk of infestation, which include both sanitation and medical (larvae extraction) measures.

Key words: Cordylobia anthropophaga, domestic cavies, myiasis, prevalence, relative risk.

\section{INTRODUCTION}

Parasites are known to be a threat to public health and as important constraints to productivity and performance in animal production [1-3]. Myiasis is a parasitic infestation of vertebrate animals and humans with the larval stages of true flies (Diptera). Myiasis has been known to occur at various sites of the body, such as the eyes, intestines, mouth, nose, urogenital tract and brain, where they survive by feeding on dead or

\footnotetext{
* Author for correspondence: Dr M. K. Kouam, Department of Animal Production, Faculty of Agronomy and Agricultural Sciences, PO Box 122, Dschang, Cameroon.

(Email: kouam@crfilmt.org.)
}

living tissues, ingested food or liquid body substances [2]. Female flies are attracted by a variety of organic compounds like sandy soils, rubbish, sod contaminated by urine or animal faeces, and skin injuries on animals $[4,5]$. The females lay their eggs in wounds or the sleeping places of the animals, especially on straw, litter and sometimes on urine-smelling clothing [6]. There are various types of myiasis [7] due to various fly species: (a) cutaneous myiasis, the most frequent form, occurs after penetration by dipteran larvae into healthy skin. Subdivisions of cutaneous myiasis include furuncular myiasis in which a furuncle-like nodule develops with one or more maggots in it, and migratory myiasis in which the maggots migrate aimlessly through burrows in the skin and 
produce numerous furuncular lesions; $(b)$ wound myiasis occurs when maggots infest open wounds such as neuropathic or vascular insufficiency ulcers, basal cell carcinoma, and psoriasis skin; $(c)$ myiasis of body cavities is characterized by the invasion of body organs such as orbit, mouth, external ears, nasal cavities, nasopharynx, vulva, vagina, bladder, lungs, or intestines by fly larvae. Cordylobia anthropophaga (also referred to as 'tumbu fly', 'mango fly', 'skin maggot fly', 'putzi fly' or 'vers de cayor') is endemic in Sub-Saharan Africa [8], causing furuncular myiasis in domestic animals [9-11] and humans [12-14].

Small rodents and dogs are considered as important reservoir hosts for the larvae of C. anthropophaga [15]. Thus, the increase in adoption of rodents such as guinea pigs (cavies) as farm animals rather than as pets or laboratory animals, is raising concern about the potential emergence of myiasis as a result of $C$. anthropophaga infestation in areas where cavy farming is fast growing. The concern is related to emergence of myiasis both as an occupational disease of cavy breeders, and as an epizootic in the cavy population. In a recent study in rural areas of the western highlands of Cameroon, C. anthropophaga was reported as one of the main parasites occurring in domestic cavies [11]. This parasite, with human and animal associations, is an important target of the One Health approach whose main goal is to minimize the impact of diseases of animal origin [16]. The One Health initiative promotes agricultural practices that prevent animal, human and environmental infections. Therefore, the objectives of this study were: (1) to determine the prevalence of myiasis induced by $C$. anthropophaga in an area where cavy breeding is fast growing in Cameroon; and (2) to determine the agricultural related risk factors associated with this infestation.

\section{MATERIALS AND METHODS}

\section{Study area and farms}

The study was carried out between June and July 2014 in the western highlands of Cameroon. The highlands are an agro-ecological zone covering the North-West and West administrative regions of the country, located between latitude $5^{\circ} 20^{\prime}-7^{\circ}$ North and longitude $9^{\circ} 40^{\prime}-11^{\circ} 10^{\prime}$ East. The North-West and West regions comprise the largest cavy production zone of the country, and accounted for $94 \cdot 10 \%$ of the national stock in 2012 [17]. The region is characterized by a high relief, and the climate is of Sudano-Guinean type. It has one rainy season, which lasts from mid-March to mid-November and one dry season from mid-November to mid-March. Humidity varies from $80 \%$ to $98 \%$. Annual precipitation ranges from 1500-2500 mm while minimum and maximum temperature are $10^{\circ} \mathrm{C}$ and $34^{\circ} \mathrm{C}$, respectively [18]. Originally, the vegetation of this region was of the savannah type but over the years due to intense crop production and animal rearing it has been transformed to a semi-degraded or degraded forest type. Nevertheless, the original vegetation can be observed in certain parts of the region which is characterized by an increasing human population growth, one of the highest in the country.

The study was conducted in privately owned farms in rural areas of the Menoua and Bamboutos border divisions (Fig.1). The farms are owned by small-scale farmers who also rear rabbits, sheep, goats, or local breeds of fowl. The housing system is either the raised floor system or in most cases, the traditional freeroaming kitchen system; in the latter system, cavies share the kitchen floor with the local fowl and/or small ruminants, and feed on kitchen waste, forage and occasionally concentrates. Forages are harvested for free as part of the natural vegetation in the compound. The breeding system is essentially semiextensive. There are very few cases of cavy keeping being intensive. In the area, $45 \%$ of farmers keep cavies as an additional source of income, $30 \%$ for manure production for backyard crop production, 20\% for meat, and $5 \%$ as pets [19].

\section{Study design and sample collection}

There is no central registry of farms in Cameroon so private farms were located and visited using a snowball sampling technique whereby a farmer, when located helped to locate the next farm and so on. The animal sample size was determined based on the formula for sample size calculation [20] as follows: $n=Z^{2} P(1-P) / d^{2}$, where $n$ is the required sample size, $Z$ is the normal deviate (1.96) at the $5 \%$ level of significance, $P$ is the estimated prevalence of infection in cavies $(50 \%)$ in absence of previous data, and $d$ is the allowable error of estimation or precision (0.05). Thus, the computed sample size $(n)$ was determined as 385. In this cross-sectional study, farms were visited once during which cavies were manually handled and carefully checked for any sign of Cordylobia ectoparastism. An animal was regarded as infested if after a careful and close inspection all over the body, there 


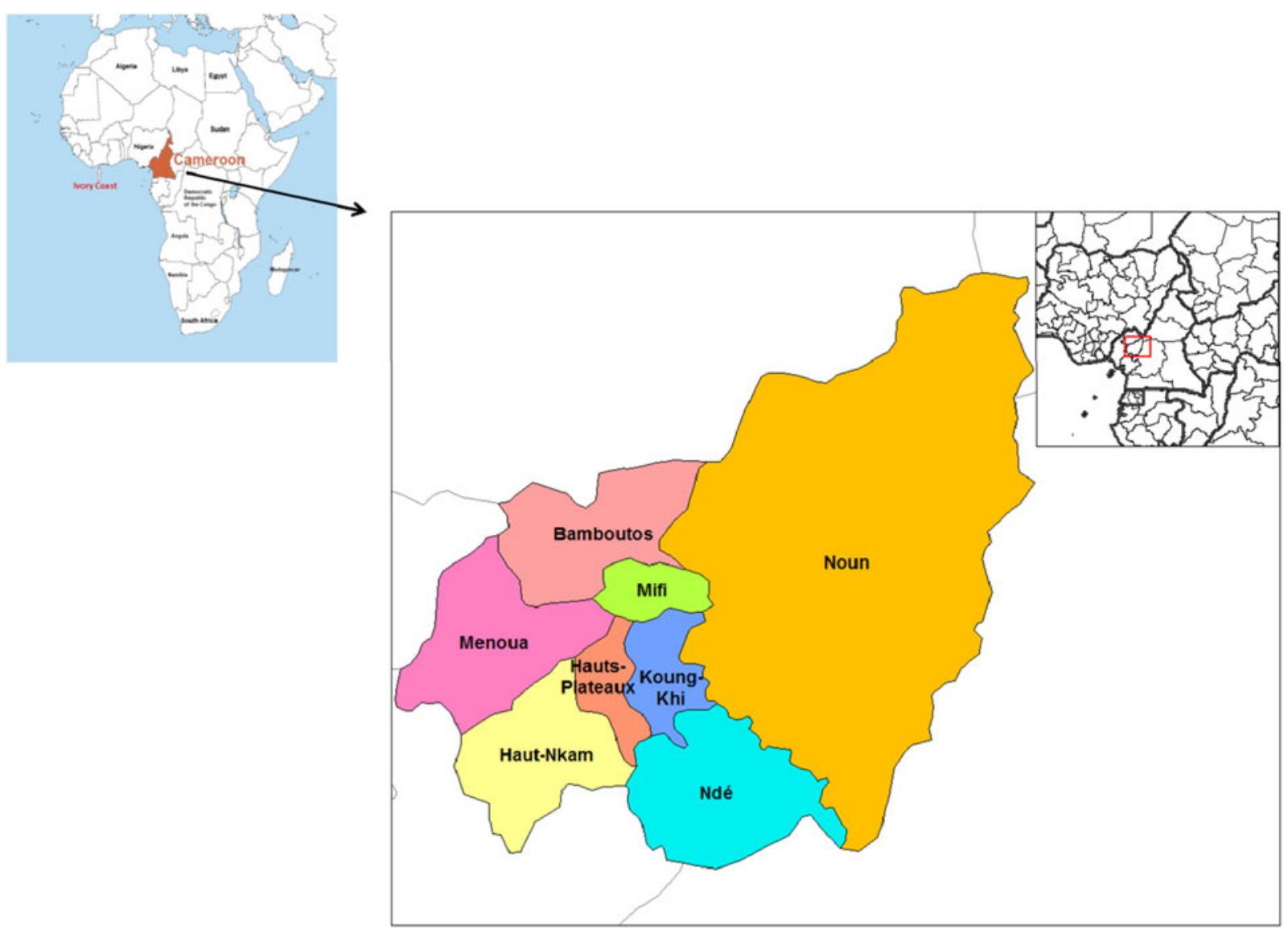

Fig. 1. Map of the West region of Cameroon showing the two divisions where sampling was carried out (Bamboutos and Menoua).

were characteristic furuncular lesion(s) recognizable by the posterior tip of the larva barely visible at the centre. The larvae from suspicious animals were expressed with finger pressure, then preserved in $80 \%$ ethanol and stored at room temperature $\left(19-22^{\circ} \mathrm{C}\right)$. When the total number of animals per farm was $>5$, five animals were randomly sampled by haphazardly capturing cavies one by one until a total of five was reached but when the number was $<5$, all the animals were sampled. In order to understand the risk factors that impact the prevalence of myiasis, animal, farm and farmer-related data were collected through a questionnaire survey (see Supplementary material). The questionnaire was administered directly to the farmer (mostly women), and the survey was conducted in French.

\section{Identification of skin larvae}

The name of the species was known already, as identified in our previous study a few months earlier [11]. Briefly, the skin larvae were identified to the genus and species level based on their morphology, using a stereomicroscope (up to $100 \times$ magnification) and following the identification key provided by Zumpt [21], and Erzinclioglu [22]. The larvae were distinguished and identified from other species of the genus Cordylobia, by focusing on the posterior spiracular apertures, the spines and the mouth hook. The characteristic openings $(n=3)$ of the posterior spiracles of C. anthropophaga are slightly curved while those of C. rodhaini are in complex curves [22].

\section{Ethical considerations}

Animals were handled humanely during sample collection, and procedures complied with international laws.

\section{Statistical analysis}

Data were analysed using descriptive statistics. The $\chi^{2}$ and the Exact tests were used to test the association between parasite infestation and various factors. 
Table 1. Relative risk of $\mathrm{C}$. anthropophaga infestation for different risk factors

\begin{tabular}{|c|c|c|c|c|c|c|c|}
\hline Factor & $N$ & $n(\%)^{*}$ & $95 \% \mathrm{CI}$ & $P$ value & $\mathrm{RR}$ & $95 \% \mathrm{CI}$ & $P$ value \\
\hline Division area & & & & $0 \cdot 20$ & & & \\
\hline Bamboutos & 141 & $6(4 \cdot 30)$ & $1 \cdot 60-90$ & & - & - & \\
\hline Menoua & 256 & $5(2 \cdot 00)$ & $0 \cdot 60-4 \cdot 50$ & & - & - & \\
\hline Owner's sex & & & & $0 \cdot 72$ & & & \\
\hline Male & 91 & $3(3 \cdot 30)$ & $0 \cdot 70-9 \cdot 30$ & & - & - & \\
\hline Female & 306 & $8(2 \cdot 60)$ & $2-5 \cdot 30$ & & - & - & \\
\hline Owner's education level & & & & $1 \cdot 00$ & & & \\
\hline University & 18 & $0(0 \cdot 00)$ & $0 \cdot 00-18 \cdot 50$ & & - & - & \\
\hline Primary school & 115 & $3(2 \cdot 60)$ & $0 \cdot 50-7 \cdot 40$ & & $1 \dagger$ & & \\
\hline Never went to school & 175 & $5(2 \cdot 90)$ & $0 \cdot 90-6 \cdot 50$ & & $1 \cdot 09$ & $0 \cdot 27-4 \cdot 49$ & $0 \cdot 60$ \\
\hline Secondary school & 89 & $3(3 \cdot 40)$ & $0 \cdot 70-9 \cdot 50$ & & $1 \cdot 30$ & $0 \cdot 27-6 \cdot 25$ & 0.53 \\
\hline Flock size & & & & $1 \cdot 00$ & & & \\
\hline$>20$ & 91 & $2(2 \cdot 20)$ & $0 \cdot 30-7 \cdot 70$ & & 1 & & \\
\hline $10-20$ & 146 & $4(2 \cdot 70)$ & $0 \cdot 8-6 \cdot 90$ & & $1 \cdot 25$ & $0 \cdot 23-6 \cdot 67$ & 0.57 \\
\hline$<10$ & 160 & $5(3 \cdot 10)$ & $0-7 \cdot 10$ & & $1 \cdot 42$ & $0 \cdot 29-7 \cdot 18$ & $0 \cdot 50$ \\
\hline Animal breed on farm & & & & $1 \cdot 00$ & & & \\
\hline Albinos & 9 & $0(0 \cdot 00)$ & $0 \cdot 00-33 \cdot 60$ & & - & - & \\
\hline Colombian & 10 & $0(0 \cdot 00)$ & $0 \cdot 00-30 \cdot 80$ & & - & - & \\
\hline Local and Colombian & 8 & $0(0 \cdot 00)$ & $0 \cdot 00-36 \cdot 90$ & & - & - & \\
\hline All breed & 12 & $0(0 \cdot 00)$ & $0 \cdot 0-26 \cdot 50$ & & - & - & \\
\hline Local & 198 & $6(3 \cdot 00)$ & $1 \cdot 10-6 \cdot 50$ & & 1 & & \\
\hline Local and albinos & 160 & $5(3 \cdot 10)$ & $1 \cdot 00-7 \cdot 10$ & & $1 \cdot 03$ & $0 \cdot 32-3 \cdot 31$ & 0.59 \\
\hline Domestic animals on farm & & & & $1 \cdot 00$ & & & \\
\hline Yes & 371 & $11(3 \cdot 00)$ & $1 \cdot 60-5 \cdot 40$ & & - & - & \\
\hline No & 26 & $0(0 \cdot 00)$ & $0 \cdot 00-13 \cdot 20$ & & - & - & \\
\hline Type of housing & & & & 0.05 & & & \\
\hline Kitchen compartment with litter & 11 & $0(0 \cdot 00)$ & $0 \cdot 00-28 \cdot 50$ & & - & - & \\
\hline Kitchen and house floor & 331 & $7(2 \cdot 10)$ & $0 \cdot 90-4 \cdot 50$ & & 1 & - & \\
\hline Cages & 32 & $1(3 \cdot 10)$ & $0 \cdot 10-16 \cdot 20$ & & 1.48 & $0 \cdot 19-11 \cdot 64$ & $0 \cdot 52$ \\
\hline Kitchen compartment without litter & 23 & $3(13 \cdot 00)$ & $2 \cdot 80-36 \cdot 60$ & & $6 \cdot 16$ & $1 \cdot 71-22 \cdot 29$ & $0 \cdot 04 \$ \S$ \\
\hline
\end{tabular}

$n$, Number of positive animals; CI, confidence interval; RR, relative risk.

* Prevalence.

$\dagger$ For a given factor, the RR of 1 indicates the reference level being compared to other levels of the factor.

\$ Significant factor.

$\S$ Factor significant even after Bonferroni correction.

Exact tests were used when an expected value was $<5$ by $\chi^{2}$ analysis. The relative risk (RR) for the presence of myiasis was computed for any factor having more than two levels. A $P$ value of $<0.05$ was considered significant. All statistics were performed using both the SPSS statistical package (version 13.0, SPSS Inc., USA) and Epi Info software (version 3.5.1, CDC, USA).

\section{RESULTS}

In total, 397 animals from 123 farms were sampled: 256 animals in 78 farms from Menoua Division, and 141 animals from 45 farms in Bamboutos Division. The overall prevalence of myiasis in animals was $2 \cdot 80 \%$ [95\% confidence interval (CI) $1 \cdot 50-5 \cdot 10]$; myiasis was found in five $(2 \%)$ and six $(4 \cdot 30 \%)$ animals in the Menoua and Bamboutos divisions, respectively (Table 1). Eleven farms $(8.90 \%)$ in total were infested with $C$. anthropophaga, with five $(6.40 \%)$ and six $(13.3 \%)$ from the Menoua and Bamboutos divisions, respectively. Application of pressure to observed lesions (furuncle) led to larva expulsion (Fig. 2), with liquefied haemorrhagic or purulent tissue (Fig. 3). Lesions were not localized to a particular site; they were common in the limbs but could be found in areas around the genitals, the belly and the neck.

Investigation of the RR of infestation within each factor having more than two levels showed that for the housing type factor, the risk of myiasis in animals kept in kitchen compartments without litter (Fig.4) 


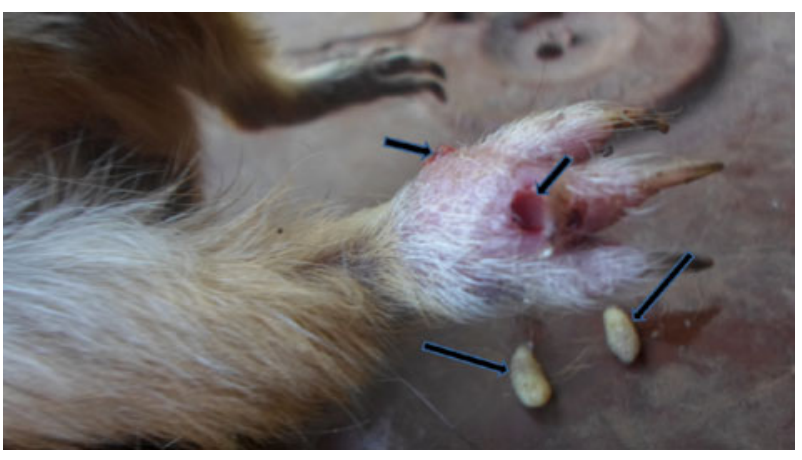

Fig. 2. Larvae expelled from a cavy's leg; note the sinuses (short arrows) after larvae extraction.

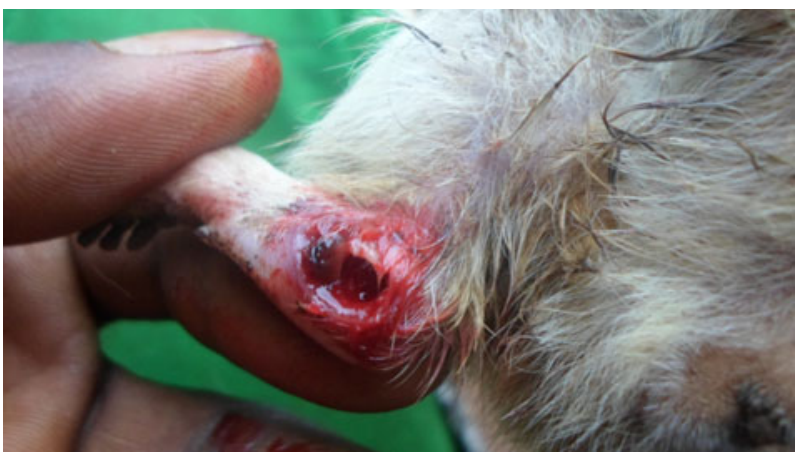

Fig. 3. Circular ulcerous furuncular lesion with haemorrhagic and purulent tissue after expulsion of a larva. The lesion is shown by the animal's owner with open hands. Note: it is common practice for farmers in the study area to remove the larvae from an infested cavy without wearing gloves.

was $6 \cdot 16$ times higher $(95 \% \mathrm{CI} 1 \cdot 71-22 \cdot 29, P=0 \cdot 04)$ than in animals kept in kitchens and house floors (Table 1).

\section{DISCUSSION}

Myiasis due to $C$. anthropophagi is known to occur in humans and other vertebrate animals. In the latter situation, cases have been reported in large mammals as well as rodents $[15,23]$, with rodents generally considered as the reservoir hosts [24] to sustain further infestation of humans and large mammals with the larvae. However, cases of myiasis in cavies (rodents) are seldom reported. In a previous study, we reported the occurrence of myiasis due to C. anthropophaga in domestic cavies reared in some rural areas in Cameroon, which suggests that domestic cavies are one of the hosts of this parasite in the country.
In this work, the main focus was to assess the importance of $C$. anthropophaga infestations in cavy stock and to determine the husbandry risk factors that sustain the infestations with this parasite. The overall prevalence of the infestation was low $(2 \cdot 80 \%)$, as well as the number of infected farms $(8.95 \%)$. This is probably an underestimate because the infestation rate of farms in the previous study was reported to be $25 \cdot 80 \%$. It may be due to the sampling methods in both studies since no attempt was made here to sample animals with obvious signs of ectoparasitism due to myiasis (limping, difficulties in moving, inability to compete for food) as was the case in the previous study. Indeed, in this study, the simple random sampling employed to determine the prevalence of infection in animals precluded a systematic sampling of obviously diseased animals that could lead to a higher prevalence at farm level. Moreover, early infestation may not be observed due to the non-conspicuous nature of the characteristic furuncle not yet developed. The previous study was conducted over a year from March 2013 to February 2014, while the present study was conducted between June and July 2014. The time period was shorter in this work than in the previous one, suggesting that climatic conditions between the two studies could influence the infestation rate of animals. To our knowledge, the seasonal dynamics of $C$. anthropophaga infestations have not yet been investigated in tropical areas, although some studies suggest that C. anthropophaga infestation is extremely common during the wet season (Curtis et al. 2006, cited in Lowe et al. [25]). The low prevalence should not be misleading and cause decision makers to consider cavy myiasis as a harmless infestation, since death of the host can occur when larvae are very close to each other; indeed where larvae are close to each other, swelling and oedema occur and the tissues may become gangrenous; the larvae may invade deeper tissues and may cause severe destruction leading to the death of the host [20]. The number of cavies (individuals) is increasing in the country, from an estimate of 30293 in 2011 to 35256 in 2012 [17]. Therefore the continuous involvement of the rural population in cavy farming might lead to an increased prevalence and intensity of C. anthropophaga infestation of cavies in the country, hence the need to design control strategies.

The risk of cordylobiasis spread was significantly higher (sixfold) in cavies housed in kitchen compartments without litter than in those moving freely on kitchen and house floors. Ecological conditions in 

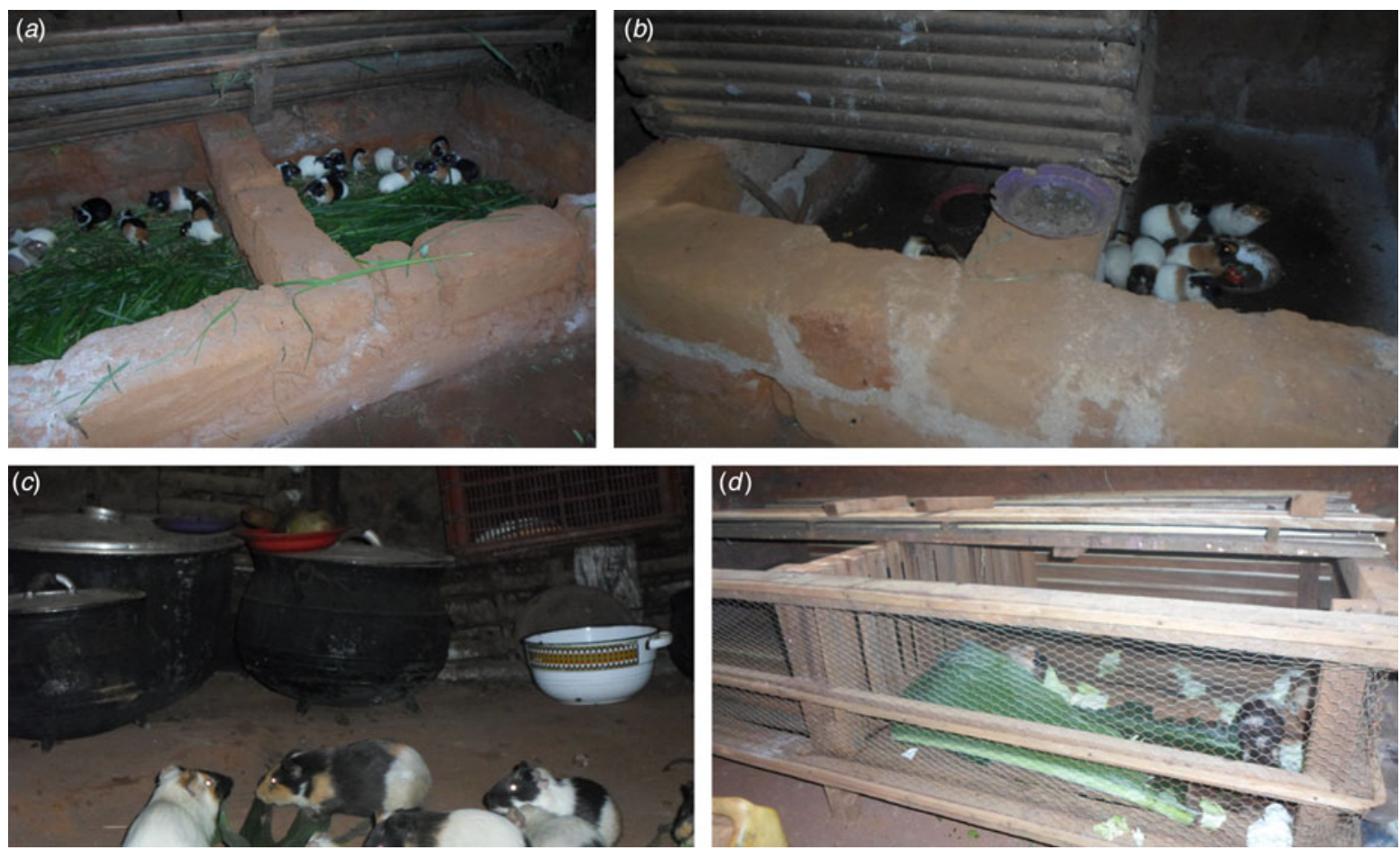

Fig. 4. Types of housing: (a) kitchen compartment with litter (the litter is covered with forage); $(b)$ kitchen compartment without litter; $(c)$ kitchen floor; $(d)$ cage.

kitchen compartments without litter are likely to be more conducive to egg laying than in other types of housing reported. Adults are known to feed on decaying fruits, decomposing animal tissues and excreta [26]. For egg laying, the female is attracted to dry sand or areas contaminated with urine or faeces [5, 26]. 'Kitchen and house floor', 'cages' and 'kitchen compartment without litter' provide such a favorable environment for egg laying because urine will either evaporate or be absorbed by the empty soil. Conversely, the environment is moist in 'kitchen compartment with litter' due to the presence of litterkeeping urine. In kitchen compartments without litter, there is a limited space for animals to move, leading to the accumulation of faeces and smell of urine on the compartment floor. This might attract more females to the compartment where forage leftover offers a dry spot to lay eggs. This is not the case in kitchen compartments with litter which, although also having a confined space, is often moist. On kitchen and house floors, even though forage leftovers may be more important, faeces and urine are not concentrated in a small area, which is attractive to females, as in kitchen compartments. Nevertheless, some entomological studies to demonstrate the relative attractiveness of different environments to female flies need to be carried out to confirm these hypotheses. The key to reducing the infestation risk will likely involves keeping females away from the living area of animals and destruction of any laying spots, through appropriate measures. These include, among others, cleaning of the animal living areas, daily removal of faeces and forage leftovers, extraction of infesting larvae and proper care of infested animals, protecting animal kitchen compartments, cages or pens with gauze wire, using mosquito bed-net materials over kitchen compartments. Unfortunately, some of these measures are difficult to implement, like the daily removal of faeces, simply because for farmers, whose main objective in cavy keeping is the production of manure [19], faeces are intentionally accumulated and removed after 1 or 2 weeks. This group of farmers in particular should be sensitized regarding the necessity to clean and remove faeces from animal housing on a daily basis

As $C$. anthropophaga infests both humans and animals, cordylobiasis is likely to be reported as an occupational disease in cavy keepers in the forthcoming years as a result of the increased interest in cavy rearing, aided by the habits of some farmers (manure producers) who disregard sanitation and preventive measures on the farms. In the present study, the 
human interface of the infestation was not investigated in cavy keepers, but this would be welcome. A sporadic case of $C$. rodhaini infestation has already been reported in the Centre region of the country [27] suggesting that both $C$. rodhaini and C. anthropophaga should be suspected in future investigations in humans.

\section{CONCLUSION}

The prevalence of the $C$. anthropophaga infestation was low, but is believed to be underestimated; hence the need to assess the burden of cordylobiasis in cavy flocks, and to assess the magnitude of infestation in cavy keepers. The relative risk of C. anthropophaga was more than sixfold higher for cavies in kitchen compartments without litter compared to cavies kept in kitchens and house floors. Although the human interface of the disease was not investigated, it is assumed that the risk for humans acquiring the disease is higher in those farmers keeping cavies in kitchen compartments without litter. As required by the One Health strategy, farmers need to be educated regarding control measures suggested to reduce the risk of infestation, which include both sanitation (good hygienic practices) and medical (extraction of larvae) measures.

\section{SUPPLEMENTARY MATERIAL}

For supplementary material accompanying this paper visit https://doi.org/10.1017/S0950268816002466.

\section{ACKNOWLEDGMENTS}

The field work of the current research work was sponsored by Cavy Project ILRI-CSIRO CSI002-GUI led by the University of Dschang and in collaboration with its partners, namely Commonwealth Scientific and Industrial Research Organization (CSIRO) and BecA-ILRI (Bioscience in eastern and central Africa - International Livestock Research Institute).

\section{DECLARATION OF INTEREST}

None.

\section{REFERENCES}

1. Hall MJR, Wall R. Myiasis of humans and domestic animals. Advances in Parasitology 1995; 35: 257-334.
2. Ogo NI, et al. Cutaneous canine myiasis in the Jos metropolis of Plateau State, Nigeria, associated with Cordylobia anthropophaga, Veterinarski Arhiv 2009; 79: 293-299.

3. Ruiz A, et al. Control strategies using diclazuril against coccidiosis in goat kids. Parasitology Research 2012; 110: 2131-2136.

4. Horen WP. Myiasis of the foot caused by Phaenicia sericata (Meigen). California Medicine 1967; 107:47-48.

5. Rice PL, Gleason N. Two cases of myiasis in the United States by the African tumbu fly, Cordylobia anthropophaga (Diptera, Calliphoridae). American Journal of Tropical Medicine and Hygiene 1972; 21: 62-65.

6. Ockenhouse CF, et al. Cutaneous myiasis caused by the African tumbu fly (Cordylobia anthropophaga), Archives of Dermatology 1990; 126: 199-202.

7. Palmieri JR, North D, Santo A. Furuncular myiasis of the foot caused by the tumbu fly, Cordylobia anthropophaga: report in a medical student returning from a medical mission trip to Tanzania. International Medical Case Reports Journal 2013; 6: 25-28.

8. Veraldi S, Brusasco A, Suss L. Cutaneous myiasis caused by larva of Cordylobia anthropophaga (Blanchard). International Journal of Dermatology 1993; 32: 184-182.

9. Ogo NI, et al. Molecular identification of Cordylobia anthropophagi Blanchard (Diptera: Calliphoridae) larvae collected from dogs (Canis familiaris) in Jos South, Plateau State, Nigeria. Onderstepoort Journal of Veterinary Research 2012; 79:349.

10. Pangui LJ, et al. Cordylobiosis in dogs in Senegal: incidence and fight against dog infestation in Dakar [in French]. Revue de Médecine Vétérinaire 2002; 153: 167-172.

11. Kouam MK, et al., Parasitic fauna of domestic cavies in the western highlands of Cameroon (Central Africa). BMC Veterinary Research 2015; 11: 288.

12. Dehecq E et al. Cordylobia anthropophaga (Diptera: Calliphoridae) outside Africa: a case of furuncular myiasis in a child returning from Congo. Journal of Medical Entomology. 2005; 42: 187-192.

13. Adisa CA, Mbanaso A. Furuncular myiasis of the breast caused by the larvae of the tumbu fly (Cordylobia anthropophaga). BMC Surgery 2004; 4: 5.

14. Kovaleva A, et al. Urogenital myiasis by Cordylobia anthropophaga. Journal of Pediatric and Adolescent Gynecology 2013; 26: e123-125.

15. McGraw TA, Turiansky GW. Cutaneous myiasis. Journal of American Academy of Dermatology 2008; 58: 907-926.

16. Pastoret PP, Vallat B. Essential veterinary education in infectious diseases of livestocks and related scientific disciplines. Revue Scientifique et Technique Office International des Epizooties 2009; 28: 537-544.

17. Cameroon, National Institute of Statistics. Cameroon Statistical Yearbook 2013 [in French]. 2013 (http://www. statistics-cameroon.org). Accessed 20 November 2015.

18. Bayemi PH, et al. Milk production in Cameroon: a review. Livestock Research for Rural Development 2005; 17: 6 . 
19. Yiva CH, et al. Cavies for income generation, manure for the farm and meat for the table. Scholarly Journal of Agricultural Science 2014; 4: 260-264.

20. Daniel WW. Biostatistics: A Foundation for Analysis in the Health Sciences, 8th edn. New York: John Wiley \& Sons, 1999, pp.782.

21. Zumpt F. Myiasis in Man and Animals in the Old World. London: Butterworths, 1965.

22. Erzinclioglu YZ. Studies on the morphology and taxonomy of the immature stages of Calliphoridae, with analysis of phylogenetic relationships within the family, and between it and other groups in the Cyclorrhapha (Diptera), Durham thesis, Durham University, 1984. (http://etheses.dur.ac.uk/7812/) Accessed 31 December 2014.
23. Devienne P, Bobard P, Pinhas C. Le Ver de Cayor, agent d'une myiase furonculeuse. Insectes 2004; 23: 135.

24. Robbins K, Khachemoune A. Cutaneous myiasis: a review of the common types of myiasis. International Journal of Dermatology 2010; 49: 1092-1098.

25. Lowe P, Naseem S, Bailey C. Cordylobia anthropophaga: a rare surgical emergency in the UK. BMJ Case Reports. Published online: 15 February 2013. doi:10.1136/bcr-2013-008659.

26. Taylor MA, Coop RL, Wall RL. Veterinary Parasitology, 3rd edn. Oxford: Blackwell Publishing Ltd, 2007.

27. Vanhecke C, et al. Facial edema caused by multifocal myiasis of Cordylobia rodhaini in YaoundeCameroon. La presse médicale 2015; 44: 564-566. 